\title{
A Preliminary Study on Efficient Agricultural Short Chain Practices in Urban Agriculture Environment of China
}

\author{
Y. XU, F. TAN ${ }^{*}$ \\ Beijing University of Agriculture, Beijing, China
}

\begin{abstract}
In developing countries, Urban Agriculture (UA) mainly focuses on providing sufficient safe food to cities. "Pick Your Own" fresh produce supply chain is one of the most popular short supply chain models in cities of China. A pilot research on fresh vegetables has been conducted in presenting situations and finding out relationship of vegetable farm households, vegetable supply chains and in calculating supply chain efficiency (DEA model has be tried). It presents the possibility of using DEA model in calculating supply chain efficiency, to guide farmer in improving practices.
\end{abstract}

KEYWORD: Short Chain; Urban Agriculture; "Pick Your Own"; Efficiency; DEA

\section{INTRODUCTION}

UA in the developed countries and areas (such as United State, United Kingdom, Germany, France, Japan, Singapore and the Netherlands etc.) mainly focus on the environment sustainability, agri-tourism and how to use high-tech to supply high-quality agri-produces. However, the main focuses of UA in developing countries are on the improvement of food quantity and security. In many developing countries located in Africa, Latin America and Asia, such as Cuba and China, UA mainly focuses on supplying enough food to cities and enhancing peoples' income by supplying agri-produces (Cai and Yang, 2008; Eriksen and Danso, 2010; Pearson et al 2010). The feature of agriculture in Beijing was "big city, small agriculture". Agriculture contributed $5.1 \%$ to Beijing economy in 1980 , but only contributed $1.1 \%$ in 2008 and $0.8 \%$ in 2012 (Yang, 2010; BSB, 2013). Data show that most farmer households were smallholders in Beijing. 89.3\% farmers' household size was less than 4 (BSB, 2013). Fresh vegetables consumed in Beijing were mainly produced outside Beijing. About 90\% fresh vegetables were distributed via wholesale market channel (Lei, et al 2010). "Pick your own" short chain has becoming popular model in Beijing. $82.1 \%$ fruit farmers sold fruits to consumers or fruit buyers within a $10 \mathrm{~km}$ zone around their farms, $13 \%$ fruit farmers were engaged in "pick your own" model. More than 70\% agri-parks operated "pick your own" format. Sales of "pick your own" fruits occupied $11 \%$ of the total fruit output of Beijing. For high-value fruits, such as cherries, in Haidian and Mentougou, "pick your own" selling occupied nearly $80 \%$ of the total output in Beijing. When it comes to consumers, $82.5 \%$ urban consumers had experienced "pick your own" in Beijing. (Liu, 2009)

\section{ADVANTAGES AND LIMITATIONS OF "PICK YOUR OWN" SHORT CHAIN}

No limitation on farm scale, small scale individual household farmers can operate; profit directly earned by farmers motivates farmers effectively; high quality, variety and geographic location can satisfy urban consumers' needs for food and leisure; encouraged by local government at present are the advantaged of the short chain. However, there are also limitations of the short chain practices. Smallholders are unclear about consumers' needs. Random transaction cannot ensure farmers a stable annual income. Farmers need to make investments on supplementary facilities (such as green houses, accommodations and canteens), which cannot be afforded by all farmers. "Pick your own" farms and agri-parks are normally far away from the city centre, which can limit the number of consumers and require development of transportation. Consumers undertake risks of personal safety when picking fruits from trees and risks of food safety when purchasing fruits/vegetables from an un-guaranteed farm. Difficult to search information of different individual farms. Farmers tend to grow similar varieties, which causes direct competition in one region. Small farm size has limited the variety growing. The limited education level of farmers (only $28.3 \%$ fruit farmers get middle school, high school or higher qualifications, $71.7 \%$ fruit farmers only have junior middle school or even lower qualifications) has limited the use of modern 
technologies (such as internet promotion)."Pick your own" model cannot help large-scale farmers to sell all their products. Standard and quality of produces cannot be guaranteed by individual household farmers. Local government has no clear supporting policies. (Liu, 2009; Liu and Zhou, 2010; Wei Xiao, 2009)

By practicing this model, on the one hand, farmers' income can be increased by selling a variety of high-value products directly to consumers and providing a wider range of services etc. On the other hand, farmers' income may be affected by random transaction, uncertain consumer number, unclear consumer needs, investments made on supporting facilities and wastes of damaged/unsold produces etc. The solution of problems cannot be recommended by one single research. The research mainly focus on how to find out influences on the short chain practice and to measure the efficiency of the short chain, in order to give suggestions on efficiency improvement.

\section{MEASURE AND IMPROVE SUPPLY CHAIN EFFICIENCY}

Several models/theories have been used in measuring supply chain efficiency and in analysing the value of a supply chain. These models include Data Envelopment Analysis (DEA) (Wong and Wong, 2007), Balanced Scorecard (BSC) (Cai, 2011; Ma, 2002), Small and Medium sized Enterprises (SME) strategy (Tenai, et al 2009), Value Chain Analysis (VCA) (Taylor, 2005) etc.. However, none of these have been used in "pick your own" short chain in UA system in a developing country like China. Therefore, DEA is using for trial in the research.

\section{METHODOLOGY}

This research focus on "pick your own" short supply chain for fresh produces grows in Beijing. It will measure the efficiency of the chain in order to improve smallholders' (smallholders here are target to farmer households) practices. The pilot research on "situation analysis of smallholders engaged in fresh vegetable supply chains" has been conducted by qualitative research in Beijing. 47 in-depth interviews have been completed. Due to the difficulties in inviting farmers' to the interviews, snow ball and judgmental sampling methods have been used together. The following parts will present the pilot research result on fresh vegetable supply chains and will use data to test DEA model. Situation of the fresh vegetable supply chains have been analysed using the Statistical Package for the Social Sciences (SPSS) and Excel. In order to use data to test the DEA model, primary data from indepth interviews have been quantified.

\section{RESULTS ANALYSIS}

\subsection{Situation of fresh vegetable households}

The majority of household size of the 47 households is between 2 and 5; the average household size is 3.7. There are only 74 people engaged in farming out of a total of 174 farmers (43\%). Only 8 households have employed workers. $96 \%$ farmers who engaged in farming are age above 41 years old. Only 13 farmer households showed their income. The highest income per person was 66,667 Yuan per year whereas the lowest was 2,000 Yuan per year. The average income per person per year was 22,141 Yuan, which is 14,328 Yuan lower than the average disposable income per urban employer per year (36,469 Yuan) (BSB 2013). 36 farmer households presented that their income from growing vegetables cannot support the expenses of their families every year. Therefore, young farmers have always been going to the city or district centres to find jobs whilst the farming activities are mainly undertaken by elder people and women in the family.

\subsection{Situation of fresh vegetable supply chain}

It is found out 26 farmer households grow vegetables for self-consumption, not for selling; 23 of these interviewees are from urban or peri-urban area; 19 of them use the same planting area to grow vegetables. This is planned by the local government. The farm size of only 13 farm households $(27.7 \%)$ is more than $667 \mathrm{~m}^{2}$ (which is $1 \mathrm{Mu}$ in China). Except for the 7 interviewees who said the local farmers plant different species, the other 40 interviewees all stated that farmers in one area normally grow similar species. These are influenced by local government and/or local market. Also, only 8 households said they would change species to grow; other households only grew same species every year. It is shown the total No. of people engaged in farming has positive correlation with production volume (coefficient 0.589) and vegetable planting area (coefficient 0.723); vegetable planting area and production volume have a positive correlation (coefficient 0.852) (Figure1). However, No. of species farmers grow and the production volume; and No. of people engaged in farming and the household size do not have correlation.

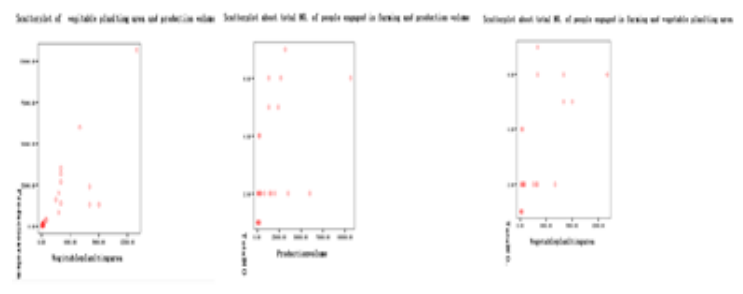

Figure 1 Relationship Between No. of People engage in Farming, Planting Area, Production Volume 
19 out of 21 farmers who sell vegetables said that the selling prices change every year; 2 of the 21 farmers were not satisfied with their current supply chain. Farmers who sell vegetables in local markets normally can decide the selling prices and hence be satisfied. Those who sell vegetables to wholesalers would accept the buying prices given by wholesalers; except for one household who was satisfied with the selling price, other households were not satisfied with the selling price at all. However, only one farmer was not satisfied with the current supply chain.

Therefore, the power of price determination strongly affects the satisfaction on selling price. It was confirmed in the Chi-Square Test, the value was 7.14 and the test was significant (0.028). The power of price determination cannot significantly affect the satisfaction on current supply chain (the value was 2.917 in the Pearson chi-square and the test is insignificant (0.233). When the farmers are not satisfied with the selling price, $60 \%$ farmers will blame the current supply chain and $40 \%$ will remain satisfied with the current supply chain. When the farmers are satisfied with the selling price, they are all pleased with the current supply chain.

Among the farmers who are not satisfied with the selling price, $60 \%$ interviewees think that the distribution channel was unstable while $40 \%$ interviewees think otherwise. However, when the farmers are satisfied with the selling price, $81.3 \%$ farmers think the distribution channel was stable.

14 farmer households in the interviews think "pick your own" is a good model to operate. The selling prices for "pick your own" vegetables were higher than vegetables sold via other channels. However, the difficulties for vegetable farmers to operate "pick your own" are: a) smallholders do not have enough land, financial and human resources to operate; b) farmers who have bigger land spaces cannot use "pick your own" channel to sell all vegetables they grow.

\subsection{Efficiency analysis}

There are 13 DMU (decision making units) which have provided annual income data have been used in measuring efficiency of the chains in pilot research by using DEA model. Due to the limitation on data collection, only two inputs and two outputs have been involved in the trial calculation. Based on efficiency calculation, only units $1,3,5,6,8,9,13$ are efficient. Efficiency of other units needs to be improved. Inefficient DMUs can use efficient DMUs as peer units to improve their efficiency. The following Table 1 takes unit 2 and 3 as examples to show the results of DEA calculation.
Table 1 DEA Results for Unit 2 and Unit 3

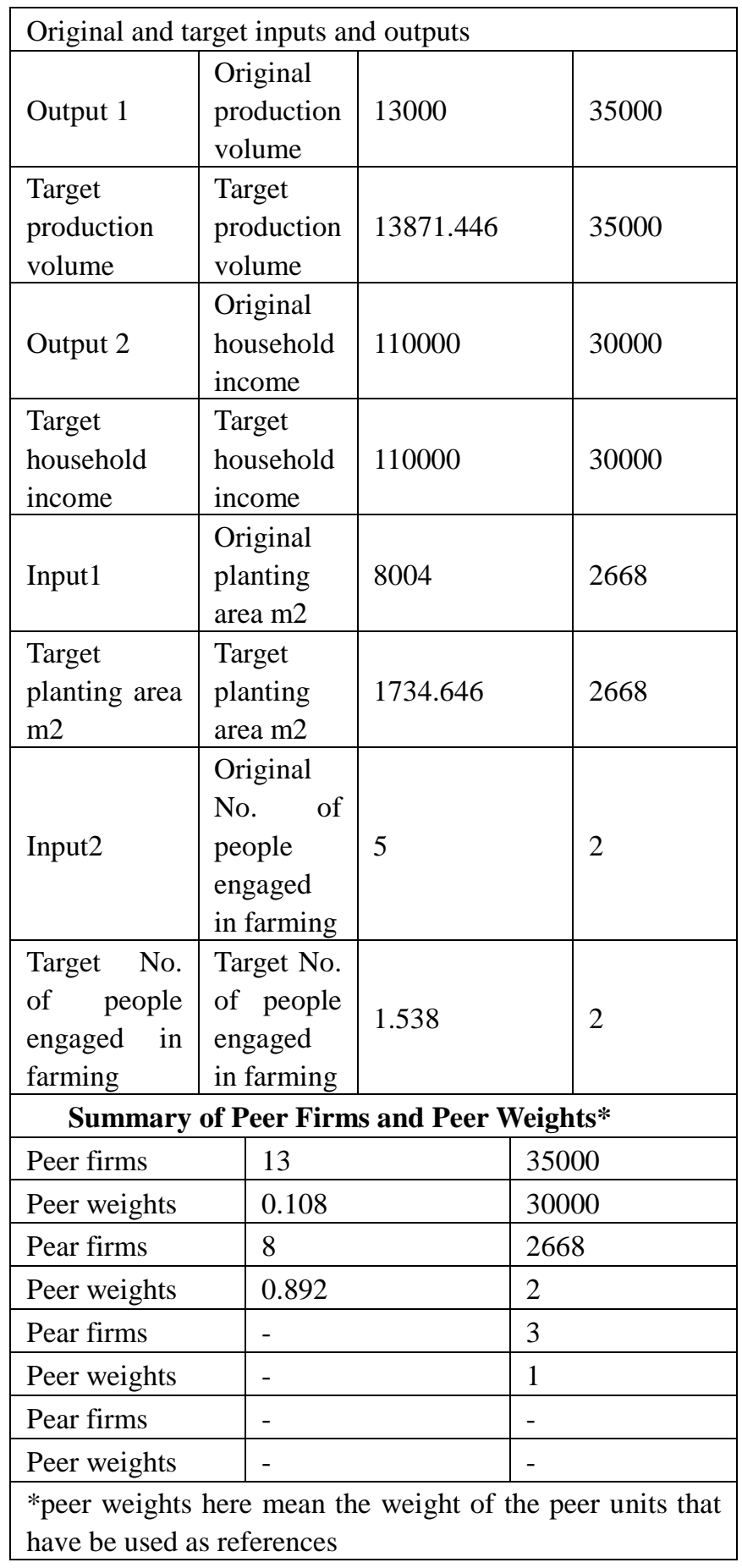

Table 2 Results of farm household 3

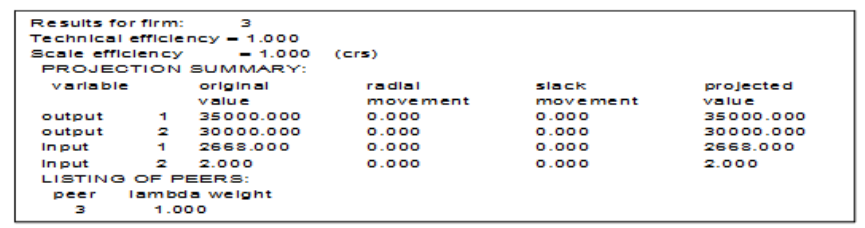

Table 3 Results of farm household 2

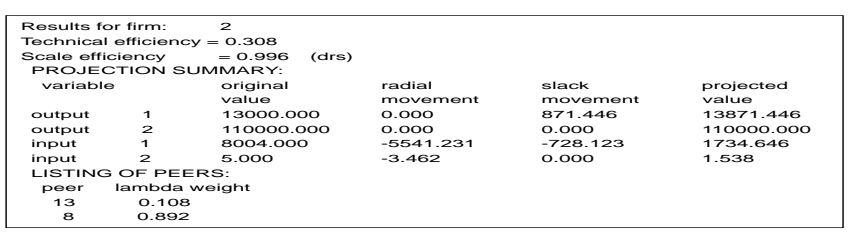


The target inputs and outputs for DEA efficient units are the same with the original number. Farm household 3 (firm 3) was a DEA efficient unit (Table 1 and 2). Farm household 2 (firm 2) was a DEA inefficient unit. Household 2 can take unit 13 and unit 8 as references to reduce areas of planting land and number of people engaged in farming, and to increase production volume to the "projected value" suggested in Table 3.

However, due to the limitations of the pilot research, the requirements for DEA calculation have not been fully satisfied. For example, the number of DMUs needs to be between two and three times of the total number of inputs and outputs. Additionally, the DEA model only considered the use of data to calculate the results, but did not take the features of data into consideration (such as in Table 3, suggest 1.538 people engaged in farming cannot be satisfied). Also, changing planting area of vegetables is another problem. Therefore, the results can only present the efficiency of the chains that can be calculated by DEA model. It needs to be considered in further research how to define effective inputs and outputs data, and how to establish the most suitable models in measuring supply chain efficiency.

\section{DISCUSSION}

Production volume and planting area of vegetables are influenced by number of people engaged in farming. The power of price determination strongly affects the satisfaction on selling price, but cannot significantly affect the satisfaction on current supply chain. When the farmers are satisfied with the selling price, they are all pleased with the current supply chain. Therefore, manage the number of people engage in farming can increase production volume and enhance area of planting. Increase farmer's bargaining power in short chain, and make farmer to decide selling price can increase their satisfaction and stable the supply chain.

Small sample size (limited number of valid DMU); insufficiently and incomplete inputs and outputs data; lake of consumer data; ignore the weight of different elements in each input or output category; strong correlation should not exist between any single input and output are the research limitations of using DEA model in the calculation. It needs to a) enlarge simple size; b) involve more inputs and outputs not only from farmers' operations but also from consumers' aspect; c) consider the features of inputs and outputs elements; d) satisfy all requirements of DEA calculation in the further research.

\section{CONCLUSION}

UA have been practiced by different countries/regions globally. Beijing has started UA for more than 10 years. There are several new models of supply chains emerging in the UA environment in Beijing; "pick your own" short chain is one of the new models. Results from pilot research of fresh vegetables have been analysed and used in the DEA model in calculating efficiency of supply chain. However, due to the limitations of the DEA model and the pilot research, the research methods, sampling methods and question design need to be carefully considered in the further study.

\section{REFERENCES}

[1] BSB (Beijing Statistic Bureau) Beijing Statistical Yearbook 2013. Beijing Statistical Information Net. http://www.bjstats.gov.cn/nj/main/2013-tjnj/index.htm [accessed 6th Jun.2014]

[2] Cai. Performance Measurement of Supply Chain Management Based on the Balanced Scorecard Value Engineering. 2011, 30 (22): 23-24.

[3] Cai, Yang. The "Experiences of International Development of Urban Agriculture". Geographical Research. 2008, 27 (2): 362-374.

[4] Eriksen and Danso, Agrionomic considerations for urban agriculture in southern cities International Journal of Agricultural Sustainability. 2010 , 86-93.

[5] Lei, He, Liu, et al. Quality and Safety Management Analysis of Beijing Vgetables in Supply Chain. Agricultural Quality and Standards. 2010, (4): 17-20.

[6] Liu, 2009 Study on Fruit Supply Chain Integration Model of Beijing. Beijing: China Agriculture Press

[7] Liu, Zhou. Analysis on the Integration Pattern of Fruit Supply Chain in Beijing. CHINESE AGRICULTURAL SCIENCE BULLETIN.2010, 26 (5): 29-35.

[8] Pearson. Sustainable urban agriculture: stocktake and opportunities International Journal of Agricultural sustainability 8 ( 1 \& 2). 2010, 7-19

[9] Taylor. Value chain analysis: an approach to supply chain improvement in agri-food chains International Journal of Physical Distribution \& Logistics Management, 35, 9/10, ABI/INFORM Global. 2005, 744-761.

[10] Tenai, Bitok, Cheruiyot et al. Moderating Variables On SME's Strategies And Competitiveness For Intemational Trade: A Survey Of Horticultural Traders In Urban And Peri-Urban Areas In Kenya The international Business \& Economics Research Journal; Dec 2009, 8/12 ABIINFORM Global , 105-114.

[11] Wei And Xiao. Research on Circulation of Agricultural Products Based on Supply Chain Management. Beijing: China Logistics Publishing House, 2009.

[12] Wong, Wong. Supply chain performance measurement system using DEA modeling Industrial Management \& Data Systems.2007, 107 (3): 361-381.

[13] Yang. Development and Discussion of the Beijing Urban Agricultural Statistics. http://www.bjstats.gov.cn/tjxh30zn/zwxd/201008/t201008 19_182628.htm [accessed 1st Aug. 2012]. 